\title{
Agile methodology of well pad development
}

\author{
Aleksandr Abramov ${ }^{1}$ (D) \\ Received: 13 July 2020 / Accepted: 24 August 2020 / Published online: 1 September 2020 \\ (c) The Author(s) 2020
}

\begin{abstract}
Placing of wells in clusters with unequal number of thereof is an emerging concept of well pad development which still requires scrutiny even from a theoretical standpoint. The concept has its potential in improving economic efficiency of one of the most capital intensive processes in upstream sector of petroleum industry - the well pad drilling. To advocate and strengthen this profitability enhancing potential, this work integrates clustering of unequal number of wells into modern project management methodologies (agile project management), which has not been done before. It is shown that such symbiosis, which is called here the adaptive well pad development (or agile methodology of well pad development), has twofold benefit consisting of (1) managing of and accounting for uncertainties of real projects and (2) further improving economic performance of development projects in comparison with standalone well pad configurations with unequal number of wells. To exemplify these advantages, detailed simulations of well pad drilling projects were performed with equal and unequal number of wells in clusters. The simulation model accounting for more than 40 parameters and individual features of wells shows that combination of unequal well clustering configurations with adaptation of well pad designs to updates in project parameters results in significant improvements to the net present value (NPV). For three drilling scenarios studied in this work, the NPV increments ranged from 8 to 36\%. Additionally, it was found that groupings with unequal number of wells consistently outperform groupings with equal number of wells in uncertain conditions, and NPV improvements from 10 to $20 \%$ have been obtained. These findings enrich understanding of the vast space of clustering schemes with unequal number of wells and demonstrate how these well pad configurations can be applied to use ever-changing environment to one's advantage. On basis of this computational study, it is now valid to assert with high degree of certainty and confidence that industrial deployment of clustering with unequal number of wells in combination with proper organizational measures results in boost to the NPV of well pad development projects at the level of several to tens of percent.
\end{abstract}

Keywords Multi-well pad $\cdot$ Drilling $\cdot$ Well clustering $\cdot$ Agile $\cdot$ Project management

\section{Introduction and basic concepts}

Development of oil and gas fields from relatively small number of pads is recognized by the industry approach to reduce the surface footprint and environmental impact and increase overall economic efficiency of the upstream projects (Demong et al. 2013). Multi-well pad drilling technology has been experiencing its renaissance over the recent years because of active development of shale formations (Calderon et al. 2015). As will be shown in this section, many authors concentrate their efforts on improving well

Aleksandr Abramov

aabramov@our.ecu.edu.au

1 School of Engineering, Edith Cowan University, 270 Joondalup Drive, Joondalup, WA 6027, Australia pad designs with respect to the following questions: (a) the overall number of wells and well pads for a given oil or gas field; (b) well spacing and well interference; (c) simultaneous operations and control of collisions; (d) clustering of well heads and well pad layout; and (e) issues related to the routine operation of well pads, see, for example, (Demong et al. 2013; Ogoke et al. 2014; Stagg and Reiley 1991).

Squeezing wells on a single pad is beneficial but creates problems with well collisions and well interference. When drilling in proximity to the already producing wells, subsurface well collisions are avoided by using a wellhead monitoring systems (Stagg and Reiley 1991). Well interference of already producing or planned to produce wells can be minimized via well spacing adjustment (Wilson 2016; Suarez and Pichon 2016; Gakhar et al. 2016; Schofield et al. 2015). One of the worst types of interference which should never 
be allowed to happen is the fracture hit. Models to predict and prevent fracture hits have been developed and applied (Molina 2017). Quantification and identification of the interference are possible via the pressure response observed at a shut-in well while changing the rates at neighboring wells of the same pad (Awada 2016). Once identified and observed interference effects do not remain the same, they are not time invariant (Manchanda 2014).

To be justified, capital intensive investments into development of well pads demand shortest delays before the first oil reaches markets. Minimization of the time to the first oil using pad completion techniques in low permeability reservoirs was achieved in (Schofield et al. 2015; Rafiee et al. 2012; Roussel and Sharma 2011). Optimization of a well pad development strategy by varying the vertical conductivity and reservoir conditions was also demonstrated in (Gakhar et al. 2016). Another direction for higher efficiency in well pad development is parallel execution of jobs. Successful implementation of drill-drill, complete-complete and drill-complete processes at once, by managing simultaneous (done within a cluster of wells) and concurrent (done within different clusters of wells) operations, was done in (Ogoke et al. 2014). Productivity of simultaneous well pad operations was also confirmed in (Awad 2015). Time savings, improved production rates and reduced environmental impact were enjoyed in an industrial application of technology to stimulate multiple pay zones and technology of simultaneous stimulation of multiple wells on the same well pad while drilling additional wells (Tolman 2009).

The above-mentioned studies, among other effects, demonstrate that well pad drilling accelerates development of oil and gas fields, but advantages of the technology are not limited to the development stage only, and they continue to manifest themselves in the daily operations. Elimination of site visits and reduction of downtime as a result of implementation of an intelligent well pad program were reported in (Krome 2015). Over a period of a field development, as practical experience accumulates and needs of construction, drilling and completion processes are satisfied and balanced, it was found to be beneficial to increase number of wells in pads (Demong et al. 2013). In provided example, an operator transformed initial 6-well pad design to a prospective 20-well pad design.

Multi-well pad drilling is thus a well-established and widely used technology, yet it seems that there is a substantial void in modern information field and literature on the subject of well pad configurations with unequal number of wells. Only recently it was shown that well pad designs with unequal number of wells in groups could be economically superior to those with equal number of wells (Abramov et al. 2018; Abramov 2019). This advantage is somewhat overshadowed by the fact that characteristics of well pad designs with unequal number of wells are determined by number of parameters with high degree of uncertainty, e.g., geological uncertainty. Over lengthy period of well pad development, these uncertainties are reduced as more precise information gets available with new wells being finished, tested and put to production. It is thus desirable to keep requirements and well pad design to be gradually emerging. The process of well pad development is tailored such that it fits into agile project management and agile product development. Agile project management concentrates on the overall management of the project which is implemented as a set of short iterations or sprints. On the other hand, agile product development concentrates on engineering activities related to the product of a project (White 2008). Within the well pad development process, the engineering activities and the iterations can be linked by deployment of unequal well clusters. It therefore follows that in modern project management (PMBOK Guide 2017), under an umbrella of agile development (Agile Practice Guide 2017), there are methodologies from which some key concepts can be borrowed and applied to well pad drilling to implement adaptive well pad development in practice.

Among the concepts which are applied to well pad drilling and development, the following three are pivotal, in order from more general to more specific. Firstly, "Adaptive development" infers that as soon as conditions and used parameters change, parts of well pad design which are still possible to change get changed accordingly. This design change is implemented in parallel with construction of the well pad. Secondly, "Progressive elaboration" implies that the design is not fixed and continuously improving to account for more accurate estimates, detailed and precise information on parameters involved into well pad development. These improvements are carried out until the pad is fully constructed. Thirdly, "Iterative development" means that one first searches for the most economically efficient design of the whole well pad and then one changes remaining parts of this design as more and more wells get finished. The first iteration requires the largest amount of work, and over time iterations get smaller and smaller.

Some other relevant for this work agile terminology as applied to the adaptive well pad development can be defined as follows. "Sprint" is a period of well pad development between consecutive reconsiderations of the design. "Backlog" is a set of renewed or updated parameters to be accounted for in the next iteration of well pad design. "Kaizen event," in a sense of a short improvement project, is an actual event of reconsidering the well pad design using content of the backlog. These definitions are given as a guideline to highlight parallels and to incite proper mindset; in practice, well pad development can be tailored such that conformity with original meaning and gist of the terms get strict, e.g., by adapting shorter sprints. 
Development of a pad within the framework of presented concepts increases dexterity in managing uncertainties, especially of geological nature as well as uncertainties of practical origin (e.g., drilling and completion durations, oil prices). This advantage comes about owing to changes made as soon as updates come up and up to the moment until modifications are possible. Such agility in turn results in enhanced profitability as demonstrated in the following sections.

\section{Concepts formalization and algorithmization}

\section{The first iteration and the initial well pad design}

To find the most efficient well pad design, a straightforward algorithm consisting of two steps is used: (1) enumeration of clustering options and (2) economic evaluation of every option. Enumeration can be done using either a recursive procedure described in (Abramov et al. 2018), or an explicit nested loop algorithm described in the next paragraph. Both methods generate sets of configurations exemplified here for a pad comprised of four wells: $\{1,1,1,1\} ;\{1,1,2\} ;\{1,2$, $1\} ;\{1,3\} ;\{2,1,1\} ;\{2,2\} ;\{3,1\} ;\{4\}$. The first configuration has four groups each including one well only, and the last configuration has four wells in a single group. The number of possible grouping options is given by $2^{\wedge}(N-1)$, where $N$ is the total number of wells. Notation used here to represent example well pad configurations is used throughout the work; in curly brackets, every number denotes number of wells corresponding to its position in the list cluster.

The explicit nested loop algorithm enumerates the clustering options in the following way. There are $N$ variables representing the number of wells in each group (cluster): $n_{\mathrm{i}}, i=1,2, \ldots N$, where $N$ is the total number of wells. Each variable takes a value from zero to $N$, and step size is one. The sum over all the variables exactly equals $N$, if not the combination (set) is rejected. In every set of variables, zero values are ignored. All sets constructed in this way are the clustering options transferred to the economic evaluation.

In the economic evaluation step, three main phases of well pad development are simulated, which may overlap in time: (1) landfilling construction, (2) drilling and completion of wells, (3) well pad production period. Initial landfilling construction is modeled as a project implemented before the drilling of the first well. The construction proceeds at a constant speed in cubic meters of landfill (material or soil) a day. The landfill length is determined by two parameters: the distance between the wells and distance between the groups of wells. Drilling of the first well starts after mobilization of the rig. Wells are drilled one after another, when the drilling of a well is finished, and the drilling rig is moved to the next well of the same group or the first well of the new group. When all the wells of a group have been drilled, completion of the first well of this group commences. Completion and tie-in operations are then done sequentially for the remaining wells of the group. Once the wells have been drilled and completed, they start producing according to their performance characteristics, the starting oil flow rate, production decline rate, initial water cut.

Different well pad configurations have different economic performances as they require different lengths of the landfilling depending on well clustering scheme and distances between wells and groups of wells, and the latter is longer than the former; also, within a well pad configuration, completion of wells and production begins only when all wells of a cluster have been drilled and the rig moved to the next cluster, so the number of wells in every cluster matters. There is thus a competition between length of the landfilling, its cost and time to the first oil and peak production, with all mentioned parameters being defined by the clustering of wells. The smaller the clusters, the longer the landfilling and the shorter the time to the first oil and peak production.

Following the economic evaluation, which takes into account outlined effects, the well pad configuration which maximizes NPV is selected as the initial design.

\section{Further iterations and the corrected well pad designs}

In subsequent iterations, one seeks to correct existing well pad design by taking into account newly available information as soon as it appears. This information includes updated values of parameters which were used to identify previous optimal design, either initial or already corrected. There are design elements which cannot and can be changed. The former ones are configurations of clusters of wells which have their wells drilled. These wells may not be completed by the time the design is reconsidered, but the fact that they have been drilled prevents from making changes to the design in this area of the pad. The only sensible thing to do with those wells is to complete them as soon as possible, unless it is apparent that the wells are dry. On the other hand, the design elements which can be changed are configurations of clusters of wells to be drilled and of the cluster which is being drilled at the moment. This latter cluster is special as it only can have number of wells which have already been drilled plus the well being drilled or more. A number of wells in this cluster, number of remaining clusters and number of wells in those clusters are the parameters which maximize the NPV, and they have to be found.

In Fig. 1, the well number three of the cluster three, which is the eleventh well of the pad, is the well being drilled. Clustering of wells one through eight cannot be changed. Holding limitation on overall number of wells in the pad, 


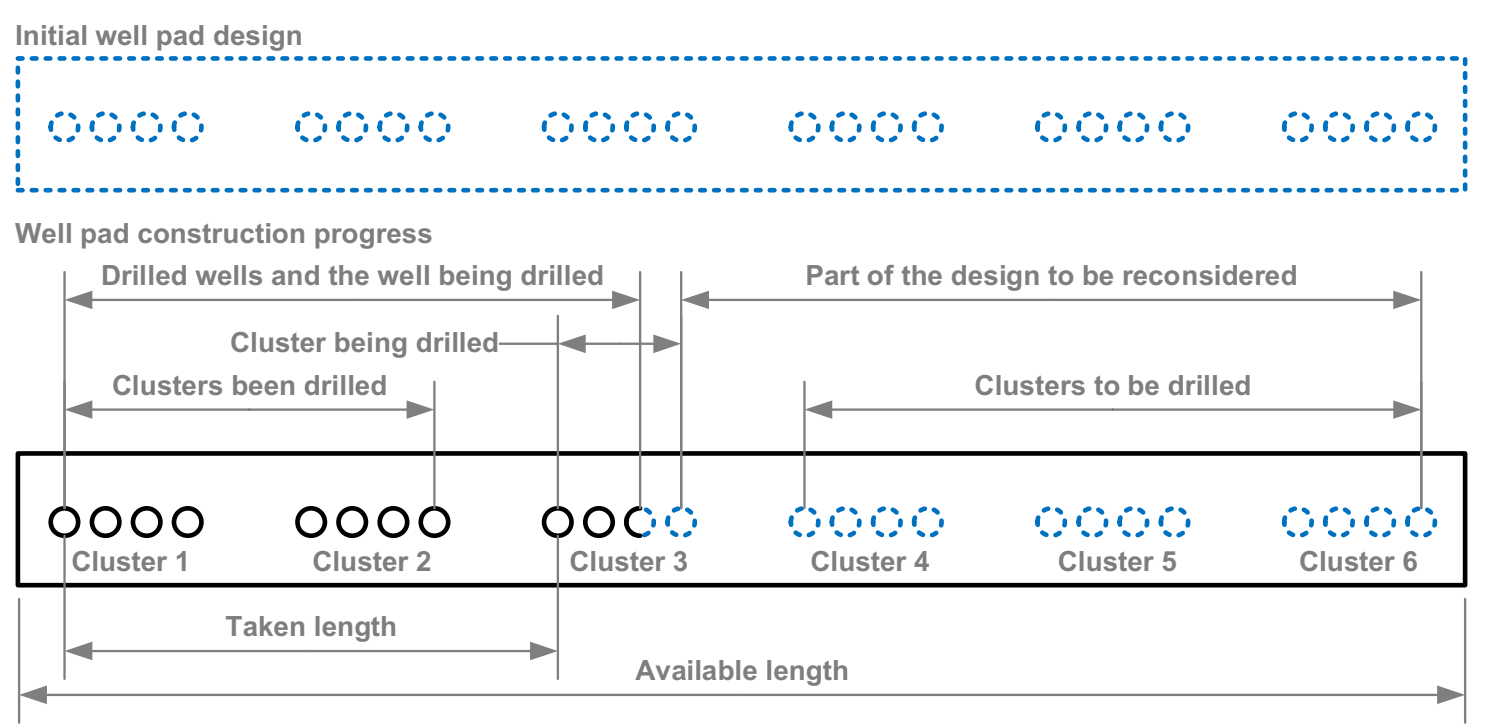

Fig. 1 Initial well pad design (top) and construction progress (bottom) up to the point of design reconsideration

clustering of wells nine through twenty four can and should be corrected as it is yet to come to existence. Note that the taken length extends up to the third cluster because one yet to make a decision on number of wells in this cluster, it has to be three or more.

The above formulation of the well pad design reconsideration problem allows us to use previously developed methodologies and algorithms, including enumeration and economic evaluation, supplementing them with few new variables. In the first place, a configuration of the unchangeable part of the design must be known. The remaining part of the design can next be determined by enumerating all possible configurations of wells and by comparing economic performances of those configurations. Then, available length of constructed landfilling has to be known too so that a decision on extending the landfilling can be made. Construction of the extra landfilling is modeled as if it occurs in parallel with drilling of the unfinished well of the unfinished cluster and the cost of this construction is accounted for starting from the next day of drilling of this unfinished well. By so doing, one penalizes all well pad configurations requiring extra landfilling, see Fig. 2. Among all reconsidered in the described way designs the grouping of wells which maximizes NPV is selected as the corrected design. Over the period of well pad development, such design corrections can be made several times.

To facilitate understanding of described material, it is helpful to interpret drawings presented in this section as timelines: from the left, the origin and the past-where construction starts and goes on, to the middle section-where construction progresses and reaches its current state-the

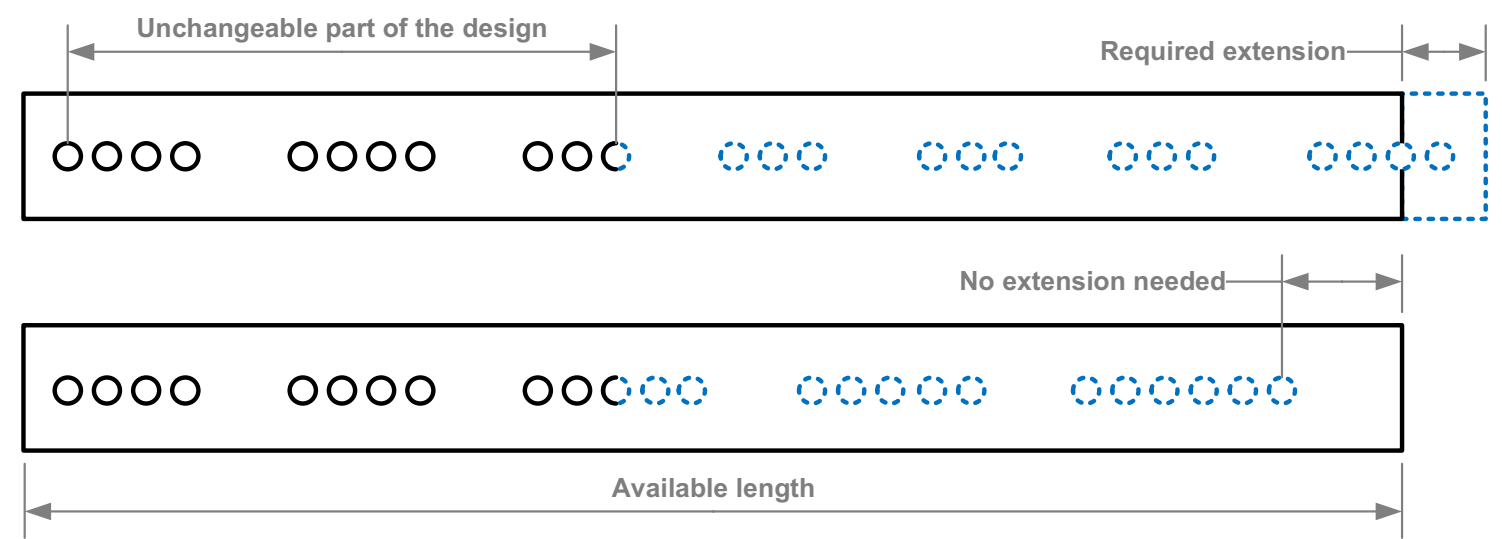

Fig. 2 Illustration of situations where configurations of wells may (top) or may not (bottom) need a landfilling extension 
present, to the right-where construction will continue and end-the future.

\section{Computational details and the reference design}

A concise description of the process of well pad construction and drilling which is modeled here was given in the previous section. Technical and economic parameters used in the modeling and computations reported in this paper are provided in Table 1. In comparison with the model which was used in the previous work (Abramov et al. 2018), the current version additionally accounts for initial gas-oil ratio, gas-oil ratio increment, price of gas, drilling rig mobilization cost, well pad decommissioning cost, and for parameters necessary to model design changes. The latter ones are available landfill length, unfinished well number and unfinished well drilling day. Counting possibility to shut-in wells after certain period of time (not used in this work), overall number of parameters of the simulation model reaches 41 , out of which 14 are set individually for every well.

The NPV of a drilling project is calculated using parameters given in Table 1 according to:

$\mathrm{NPV}=\sum_{t=0}^{T} \frac{\mathrm{CF}_{t}}{(1+d)^{t}}$,

where $t$ is the time of the cash flow; $T$ is the number of time steps; $\mathrm{CF}_{t}$ is the net cash flow (difference between cash inflow and cash outflow at time $t$ ); and $d$ is the discount rate. Positive cash flow (cash inflow) of every considered well pad drilling project results from selling of produced oil and gas. Negative cash flow (cash outflow) composes of three parts: well pad construction cost (including rig mobilization/ demobilization, rig shifts); well drilling and completion cost (assumed to be paid before every operation); and operational expenditures depending on liquid production. Taxes are not taken into account. Investment and construction timelines, NPV profiles are illustrated for several case studies projects in the next section, see Fig. 4 through Fig. 9. It is assumed that existing surface facilities have enough capacity to process produced liquid regardless of well clustering scheme.

For the purpose of the following presentation and to avoid ambiguity, it is important to formally introduce three definitions: the reference design, the initial design, the corrected design and relations of thereof.

The reference design-the optimal design, with equal number of wells in groups is found for initial conditions (set of parameters). Some examples of possible reference designs for a 24-well pad are $\{3,3,3,3,3,3,3,3\},\{4,4,4,4,4,4\}$ and $\{6,6,6,6\}$; only one of those designs has the highest NPV in given conditions. It is essential to remember that the search for this design is performed within limited space of designs with constant number of wells in clusters in initial conditions (set of parameters). This design is chosen as the reference design because this is what industry most likely would use in the best-case scenario (Abramov et al. 2018).

The initial design-the optimal design with unequal number of wells in groups is found for initial conditions (set of parameters). In general, the initial design has unequal number of wells in groups, but in some cases, it could have equal number of wells. The crucial thing to keep in mind is that the search for this design is performed within full space of designs with varying and constant number of wells in clusters in initial conditions (set of parameters).

The corrected design-corrected optimal well pad configuration with unequal (in general) number of wells is found within full space of designs with varying and constant number of wells in clusters in updated conditions (set of parameters) accounting for unchangeable parts of the previous optimal configuration.

In principle, a well pad design can be corrected as many times as needed until development of a pad is not finished. In this work, three scenarios for which conditions (set of parameters) are updated at three different moments in time: "early," "late" and "later" (defined in the next section) are considered. For the sake of conciseness and simplicity, only the starting flow rates of oil are updated.

\section{Drilling scenarios, the change and its timing}

Three drilling scenarios for which the reference and the initial designs are found differ from each other by the starting flow rates of oil, see Fig. 3. For scenario 1 (S1), oil starting flow rates of wells 1-12 are $90 \mathrm{tn} /$ day and of wells 13-24 are $20 \mathrm{tn} /$ day. For scenario 2 (S2), oil starting flow rates of wells $1-12$ are $20 \mathrm{tn} /$ day and of wells 13-24 are $90 \mathrm{tn} / \mathrm{day}$. For scenario 3 (S3), oil starting flow rates of wells 1-8 are $20 \mathrm{tn} /$ day, of wells $9-16$ are $50 \mathrm{tn} /$ day and of wells $17-24$ are $90 \mathrm{tn} /$ day.

The reference and the initial designs for three scenarios are collected in Table 2. These are the NPV maximizing well pad configurations, definitions of these configurations (designs) are given in "Computational details and the reference design" section of this paper, the search procedure is described in "Concepts formalization and algorithmization" section, and analysis and characteristics of these designs are presented in "Results of computations and discussion" section. The reference and the initial designs in Table 2 are the designs maximizing NPV of drilling projects with parameters in Table 1. The reference design is found among groupings with constant number of wells, and the initial design is found among all $2^{\wedge} 23$ possibilities. 
Table 1 Parameters of the simulation model

\begin{tabular}{|c|c|c|}
\hline Technical and economic parameters & Units & Values \\
\hline \multicolumn{3}{|l|}{ Landfill design and construction parameters } \\
\hline Distance between wells & meter & 5 \\
\hline Distance between groups of wells & meter & 15 \\
\hline $\begin{array}{l}\text { Distance from the first and the last wells of the pad to the } \\
\text { landfill border }\end{array}$ & meter & 80 \\
\hline Landfill width & meter & 75 \\
\hline Landfill height & meter & 2 \\
\hline Landfill construction speed & $\mathrm{m}^{3} /$ day & 600 \\
\hline Drilling rig mobilization time & day & 30 \\
\hline Landfill specific cost & $1000 \mathrm{RUB} / \mathrm{m}^{3}$ & 10 \\
\hline Fixed cost of pad construction & 1000 RUB & 100000 \\
\hline Well pad decommissioning cost & 1000 RUB & 100000 \\
\hline \multicolumn{3}{|l|}{ Drilling and completion parameters } \\
\hline *Well drilling time & day & 30 \\
\hline *Well completion time & day & 20 \\
\hline$*$ Well drilling cost & 1000 RUB & 50000 \\
\hline *Well completion cost & 1000 RUB & 30000 \\
\hline Drilling rig short shift duration & day & 1 \\
\hline Drilling rig long shift duration & day & 2 \\
\hline Drilling rig demobilization time & day & 10 \\
\hline Drilling rig short shift cost & 1000 RUB & 1700 \\
\hline Drilling rig long shift cost & 1000 RUB & 2600 \\
\hline Drilling rig mobilization cost & 1000 RUB & 10000 \\
\hline Drilling rig demobilization cost & 1000 RUB & 10000 \\
\hline \multicolumn{3}{|l|}{ Technological parameters of wells } \\
\hline Number of wells & units & 24 \\
\hline *Starting oil flow rate & tn/day & $20,50,90$ \\
\hline *Oil production decline rate & $\% /$ year & 70 \\
\hline *Initial water cut & $\%$ & 1.5 \\
\hline *Liquid production increment & $\% /$ year & 0.3 \\
\hline *Well shut-in water cut (water cut at well shut-in) & $\%$ & 90 \\
\hline *Initial gas-oil ratio & $\mathrm{m}^{3} / \mathrm{tn}$ & 300 \\
\hline *Gas-oil ratio increment & $\% /$ year & 0.1 \\
\hline$*$ Oil density & $\mathrm{kg} / \mathrm{m}^{3}$ & 850 \\
\hline *Water density & $\mathrm{kg} / \mathrm{m}^{3}$ & 1010 \\
\hline \multicolumn{3}{|l|}{ Economic parameters } \\
\hline Price of oil & $1000 \mathrm{RUB} / \mathrm{tn}$ & 12 \\
\hline Price of gas & $1000 \mathrm{RUB} / 1000 \mathrm{~m}^{3}$ & 1 \\
\hline Specific operational expenditures (liquid based) & $1000 \mathrm{RUB} / \mathrm{m}^{3}$ & 1 \\
\hline Discount rate & $\% /$ year & 15 \\
\hline Time step & day & 1 \\
\hline Modeling period & years & 20 \\
\hline
\end{tabular}

*Parameters which are set for every well individually

1 USD (United States Dollar) 70 RUB (Russian Ruble)
Construction schedules of the reference design well pads for scenarios S1, S2 and S3 are shown in Figs. 4, 6 and 8 , respectively; their corresponding production and NPV profiles are shown in Figs. 5, 7 and 9. The initial and the corrected designs have analogous representations of the simulation outputs only adding obvious variations reflecting changes in well clustering schemes.

Within the schedule diagrams (Figs. 4, 6 and 8), horizontal lines represent sequence of jobs and their durations. Drilling of wells is almost uninterruptable, and breaks occur 


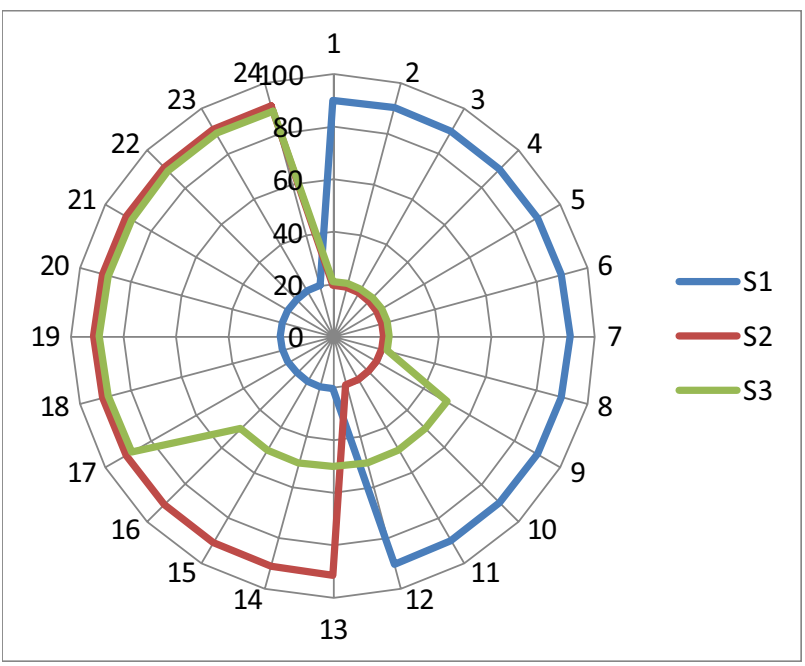

Fig. 3 Starting oil flow rates (tn/day) of every well of a 24-well pad for three scenarios S1, S2 and S3 (numbers 1 to 24 enumerate wells, with flow rates being measured along the radial direction)

Table 2 The reference and the initial designs for three drilling scenarios (well pad configurations are shown in curly brackets, and a number of wells in every cluster are separated by commas)

\begin{tabular}{llll}
\hline Design\Scenario & S1 & S2 & S3 \\
\hline Reference design & $\{4,4,4,4,4,4\}$ & $\{4,4,4,4,4,4\}$ & $\{6,6,6,6\}$ \\
Initial design & $\{3,3,3,3,12\}$ & $\{12,3,3,3,3\}$ & $\{9,5,4,3,3\}$ \\
\hline
\end{tabular}

when the rig moves from well to well (short shifts) or from cluster to cluster (long shifts). It is seen that completion of wells of a previous cluster is done in parallel with drilling of wells of a next cluster, and those groups of four (Figs. 4 and 6) or six (Fig. 8) lines after long shifts of the rig show well completion one by one. When the rig is demobilized and the last four or six wells are completed, the well pad is at the peak of oil and gas production ( $\mathrm{S} 1$ is an exception as the last twelve wells have low oil starting flow rate) and enters the decline stage apparent in Figs. 7 and 9.

Vertical needle-like lines in Figs. 4, 6 and 8 represent investments into well pad development activities. Major investments happen just before every operation. Regular frequency spikes seen over almost whole period of pad development at the level of $50 \mathrm{mln}$ RUB are investments into well drilling, sometimes they coincide with repetitive spikes at the level of $30 \mathrm{mln}$ RUB, and these are investments into well completion. Other easily identifiable investments are those required for rig mobilization/demobilization and movements, and the fixed cost of pad construction. There is steady level of funds pumped into the project in the beginning when the landfilling gets built. Landfilling construction and rig mobilization are done before the moment when drilling of the first well begins, which is the time zero moment. The profile diagrams in Figs. 5, 7 and 9 start from the time zero; their jags reflect all significant events of every well completion and commencement of production, well shut-in and the end of the project with the final miniature slumps in the NPV profiles corresponding to the decommissioning.

Updated conditions which are used to search for corrected well pad designs are derived from $\mathrm{S} 1, \mathrm{~S} 2$ and $\mathrm{S} 3$ by replacing $20 \mathrm{tn} /$ day starting flow rates with $90 \mathrm{tn} /$ day and vice versa, see Fig. 10. These updated sets of parameters are denoted as $\mathrm{S}^{\prime}, \mathrm{S} 2^{\prime}$ and $\mathrm{S} 3^{\prime}$. Such a dramatic change is chosen intentionally to amplify the effect of well pad design corrections.

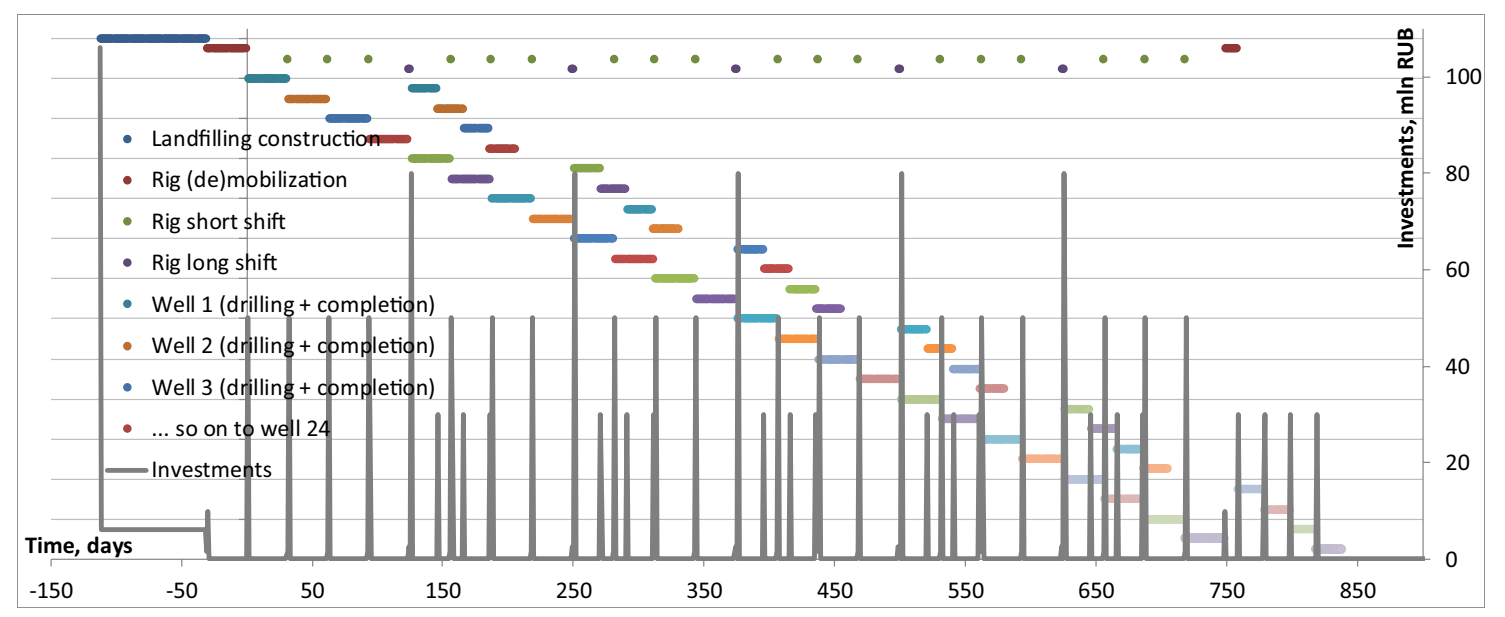

Fig. 4 Scenario 1 reference design well pad construction, drilling and completion schedule with corresponding investments (the horizontal lines show time intervals of operations; vertical lines show amount of invested funds; names of operations are given in the legend; differ- ent operations are distinguished by color; drilling and completion of the same well are colored with the same shade; completion of wells begins after drilling of the whole group has been finished, when the rig has been moved to the next group) 


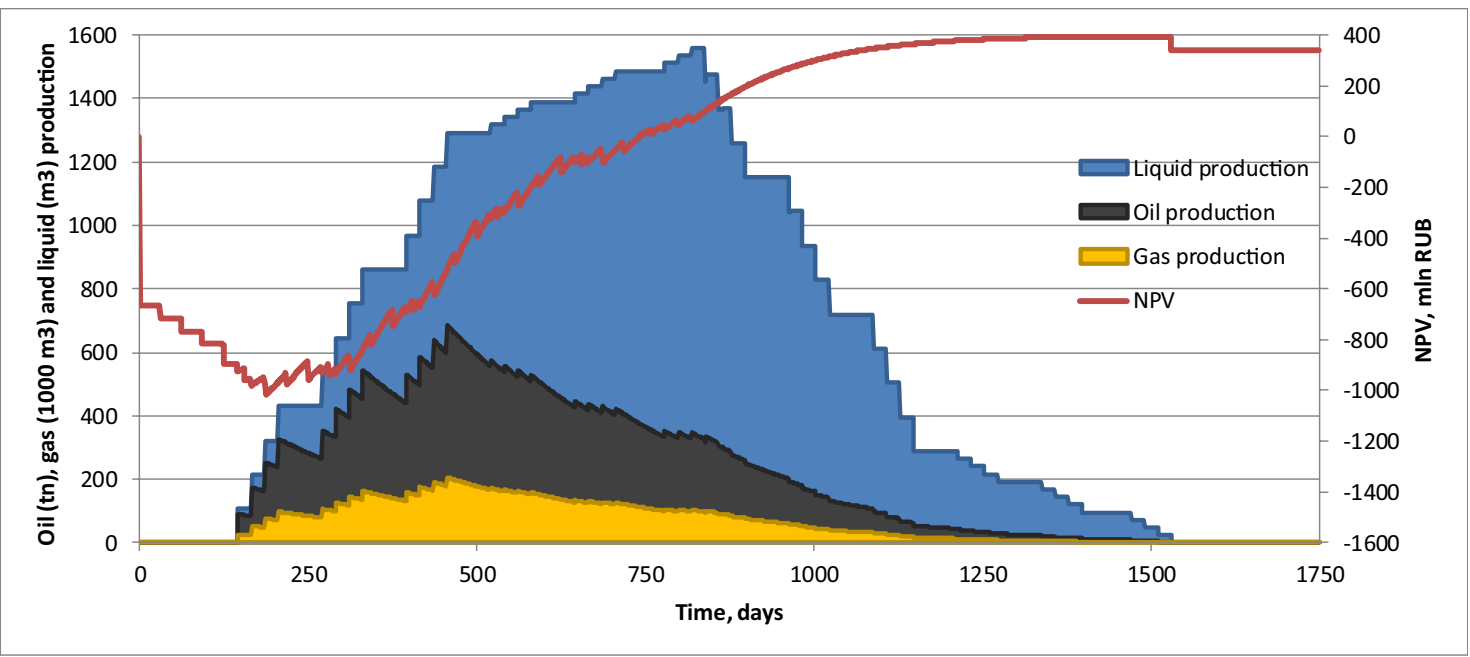

Fig. 5 Scenario 1 reference design well pad production and NPV profiles

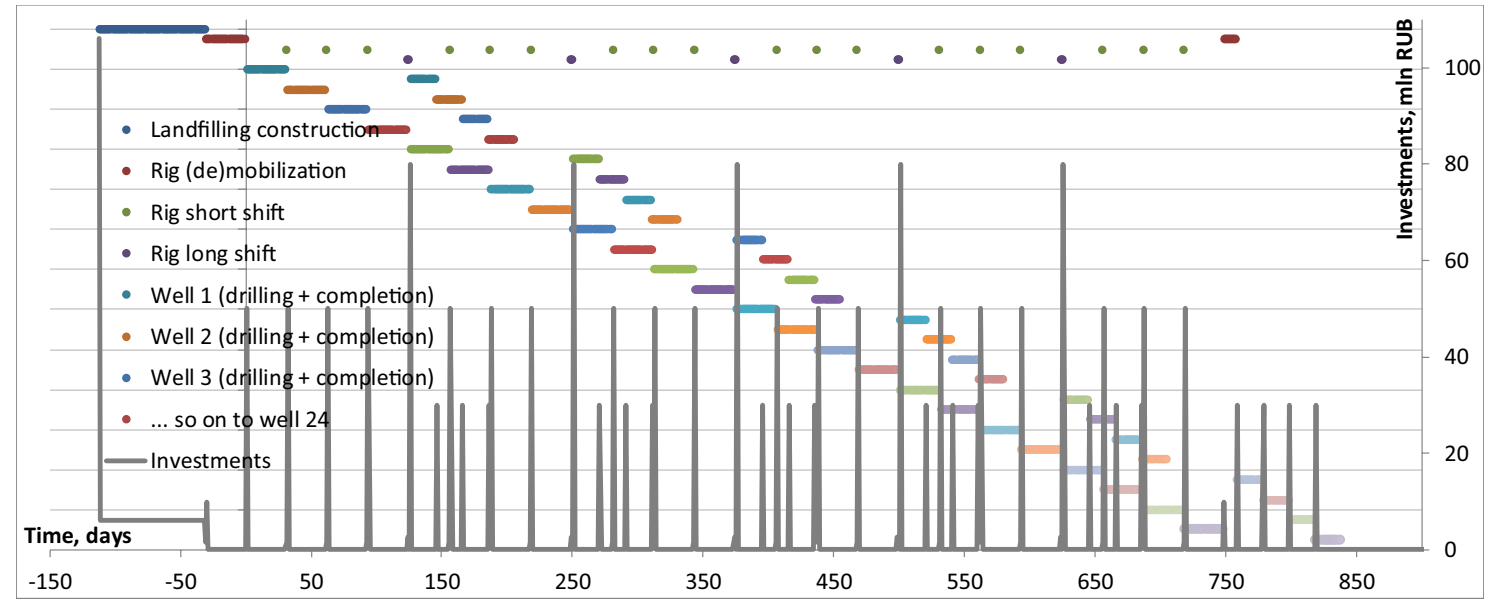

Fig. 6 Scenario 2 reference design well pad construction, drilling and completion schedule with corresponding investments (for clarification, see caption of Fig. 4)

It is obvious that the earlier corrections to a well pad design are made, the stronger the positive effect of such corrections will be. To quantitatively substantiate this statement, a search is performed for corrected designs in three moments in time: "early"-_ay 10 of drilling well 4; "late"-day 10 of drilling well 15; "later"-_day 10 of drilling well 21. As a reminder, it should be mentioned that parts of the designs up to wells 4, 15 and 21, respectively, are fixed as they were in the corresponding initial well pad designs.

\section{Results of computations and discussion}

First of all, it is important to compare performance of the reference designs with that of the initial designs in the initial conditions ( $\mathrm{S} 1, \mathrm{~S} 2$ and $\mathrm{S} 3$ ). This comparison demonstrates superiority of well clustering schemes with unequal number of wells over clustering schemes with equal number of wells. As Fig. 11 showcases, groupings 


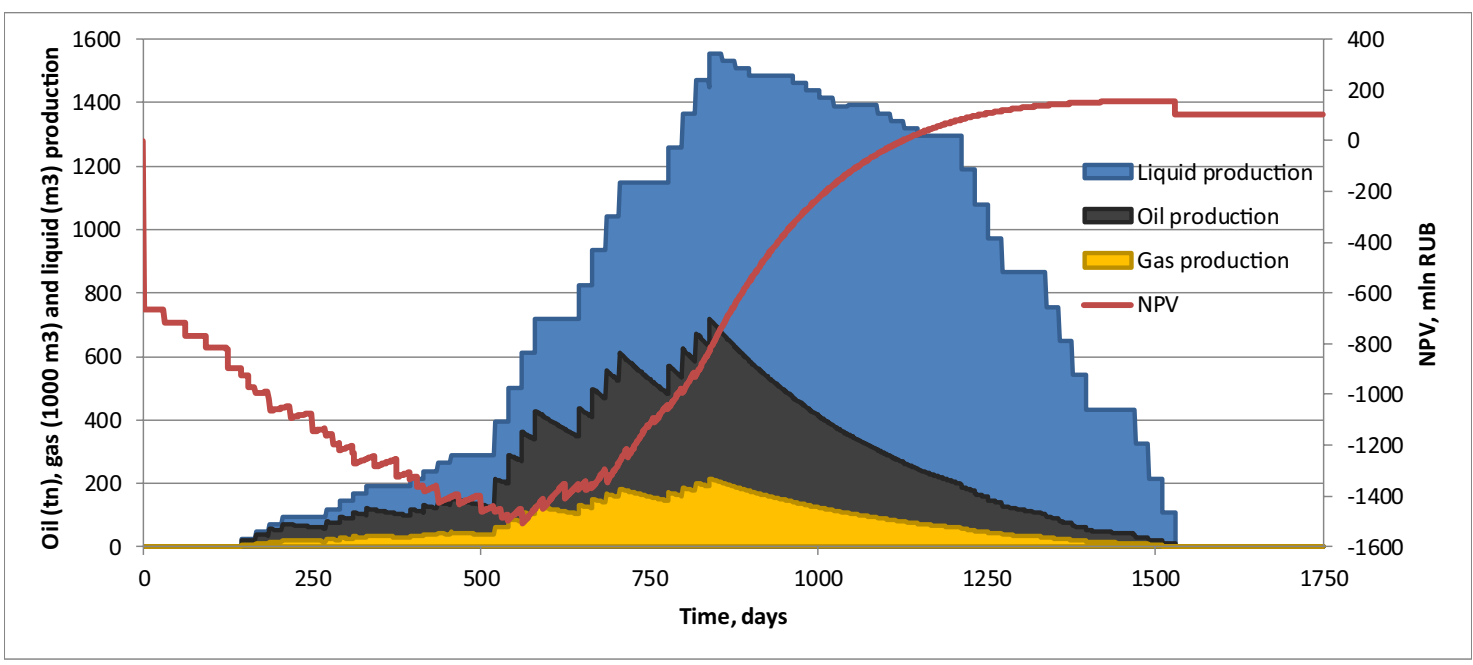

Fig. 7 Scenario 2 reference design well pad production and NPV profiles

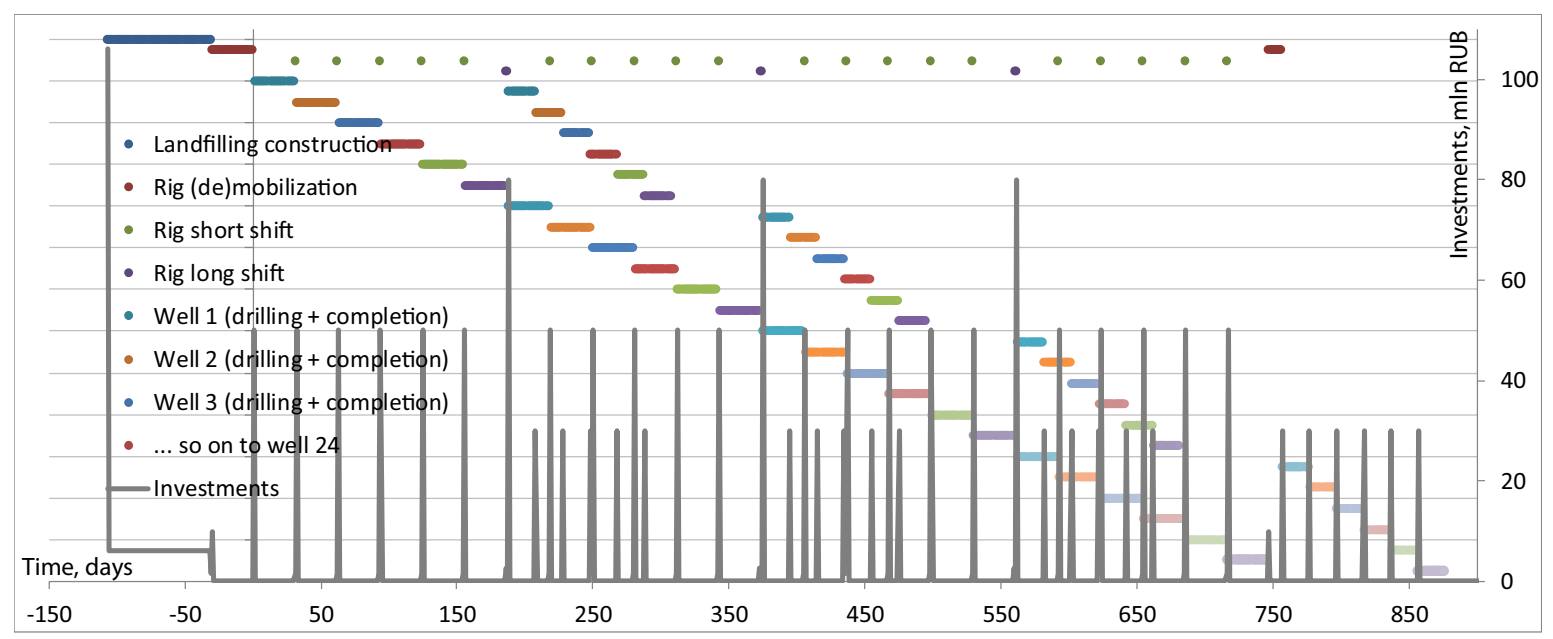

Fig. 8 Scenario 3 reference design well pad construction, drilling and completion schedule with corresponding investments (for clarification, see caption of Fig. 4)

with unequal number of wells outperform groupings with equal number of wells by $8 \%, 20 \%$ and $36 \%$, for S1, S2 and $\mathrm{S} 3$, respectively.

The corrected well pad designs for three scenarios $\mathrm{S} 1^{\prime}$, S2' and S3" and three moments in time "early," "late" and "later" are collected in Table 3. It can be seen that the later change is less flexible as those configurations are the same as the initial design configurations for $\mathrm{S} 2{ }^{\prime}$ and $\mathrm{S} 3^{\prime}$. Contrary, the early change is much more flexible, and its configurations are very different from the initial design configurations. A noticeable difference between early change $\mathrm{S}^{\prime}{ }^{\prime}$ and $\mathrm{S}^{\prime}{ }^{\prime}, \mathrm{S}^{\prime}$ ' and $\mathrm{S}^{\prime}{ }^{\prime}$, is that for $\mathrm{S}^{\prime}$, more wells per group are drilled in the beginning, whereas for $\mathrm{S}^{\prime}$ and $\mathrm{S} 3^{\prime}$, more wells are drilled in the end. This is consistent with lower flow rate wells in $\mathrm{S1}^{\prime}, \mathrm{S} 2^{\prime}$ and $\mathrm{S} 3^{\prime}$, which are grouped into larger clusters by the optimization algorithm. The same logic works for the late change, where larger clusters towards the end are observed for $\mathrm{S}^{\prime}$ and $\mathrm{S}{ }^{\prime}$, and smaller clusters for S1'.

Performance of corrected designs in comparison with initial ones is illustrated in Fig. 12. Very clear trend of delivering better economic results for earlier corrections is seen for scenario $\mathrm{S}^{\prime}$ '. The trend is preserved for scenarios $\mathrm{S} 2$ ' and $\mathrm{S} 3$ ', but is much less pronounced, and for "later" changes, no improvements are possible at all. In general, early corrected designs significantly outperform the initial designs. For scenario $\mathrm{S} 1$ ', corrected designs make initially planned drilling project economically viable by dragging the NPV into positive region. For scenario S2', almost twofold NPV improvement is observed with early corrected well pad 


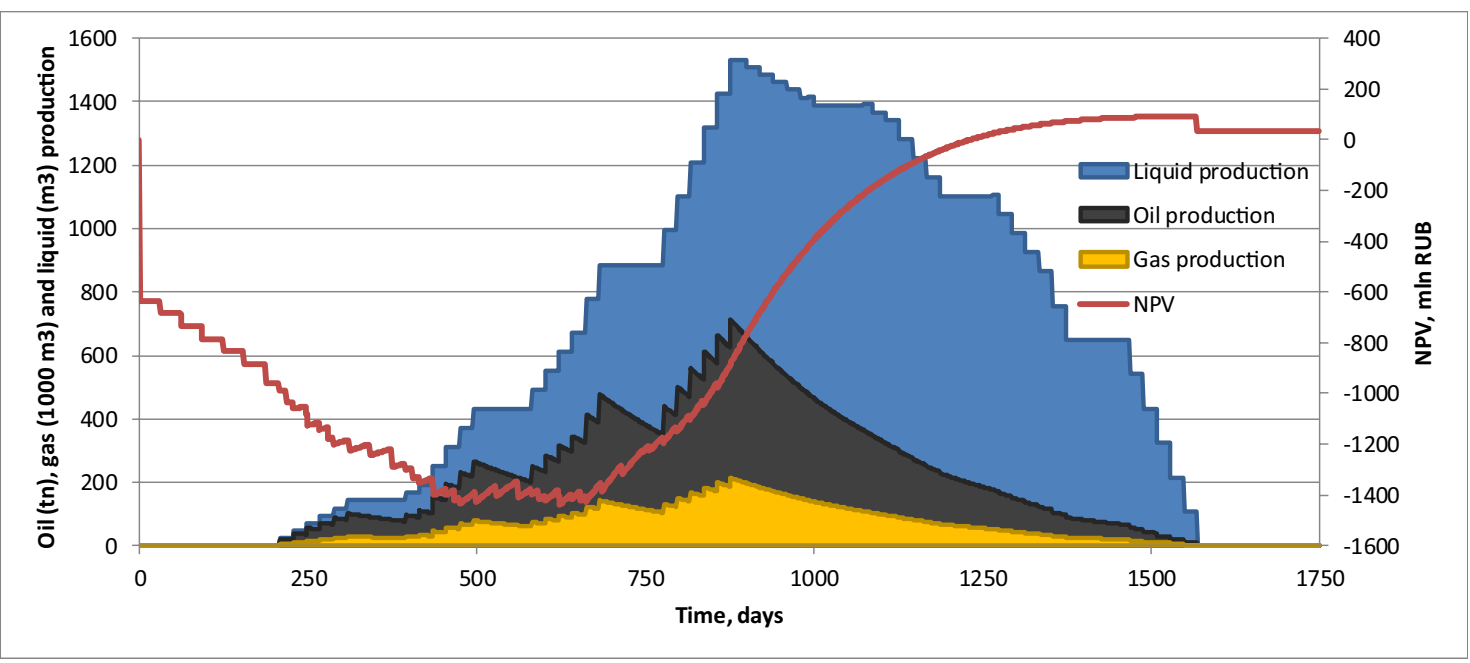

Fig. 9 Scenario 3 reference design well pad production and NPV profiles

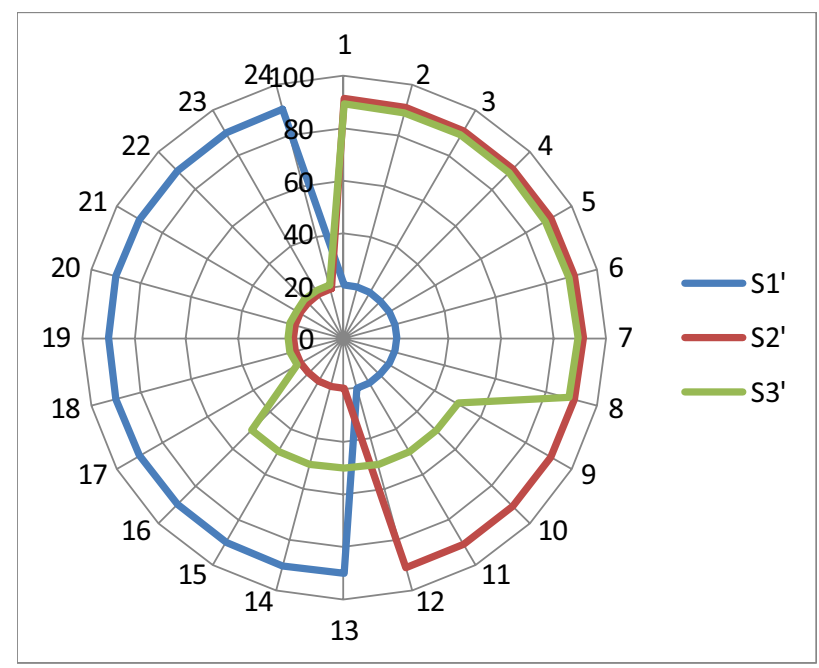

Fig. 10 Updated starting oil flow rates (tn/day) of every well of a 24-well pad for three scenarios S1', S2' and S3' (numbers 1-24 enumerate wells, with flow rates being measured along the radial direction)

configuration, $73 \%$ gain. For scenario $\mathrm{S}^{\prime}$, the gain is $37 \%$ for the same "early" change.

Not only the early corrected designs appreciably outperform the initial designs, they also beat the reference designs in updated conditions, see Fig. 13. NPV improvements reach $12 \%, 7 \%$ and $9 \%$ for scenarios $\mathrm{S}^{\prime}, \mathrm{S} 2^{\prime}$ and $\mathrm{S}^{\prime}$, respectively.

By comparing Figs. 12 and 13, an inquisitive reader may notice that the reference designs outperform the initial designs for updated conditions represented by scenarios $\mathrm{S}^{\prime}, \mathrm{S} 2^{\prime}$ and $\mathrm{S} 3^{\prime}$. Higher NPVs of the reference designs are explained by intentionally dramatic change of the starting flow rates of oil and by the fact that the initial designs have

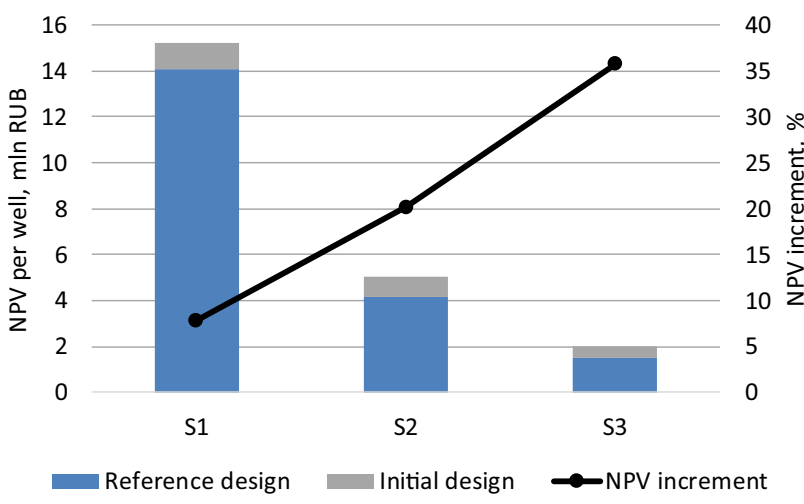

Fig. 11 Performance of the initial well pad designs in comparison with the reference designs for $\mathrm{S} 1, \mathrm{~S} 2$ and $\mathrm{S} 3$

Table 3 The initial (found for S1, S2 and S3) and corrected well pad designs for scenarios $\mathrm{S}^{\prime}, \mathrm{S}^{\prime}$ and $\mathrm{S}^{\prime}$ (well pad configurations are shown in curly brackets, and a number of wells in every cluster are separated by commas)

\begin{tabular}{llll}
\hline Design $\backslash$ Scenario & S1' & S2' & S3' \\
\hline Initial design & $\{3,3,3,3,12\}$ & $\{12,3,3,3,3\}$ & $\{9,5,4,3,3\}$ \\
Early change & $\{3,9,3,3,3,3\}$ & $\{4,2,3,3,12\}$ & $\{4,3,4,5,8\}$ \\
Late change & $\{3,3,3,3,3,3$, & $\{12,3,2,3,4\}$ & $\{9,5,2,3,5\}$ \\
& $3,3\}$ & & \\
Later change & $\{3,3,3,3,9,3\}$ & $\{12,3,3,3,3\}$ & $\{9,5,4,3,3\}$ \\
\hline
\end{tabular}

not been corrected to account for the updates. Early corrections to the initial designs (Fig. 13) demonstrate that the reference designs (equal number of wells in clusters) are not better in changing or uncertain conditions. Instead, the proper conclusion would be that the configurations with unequal number of wells in clusters are determined (optimized) 


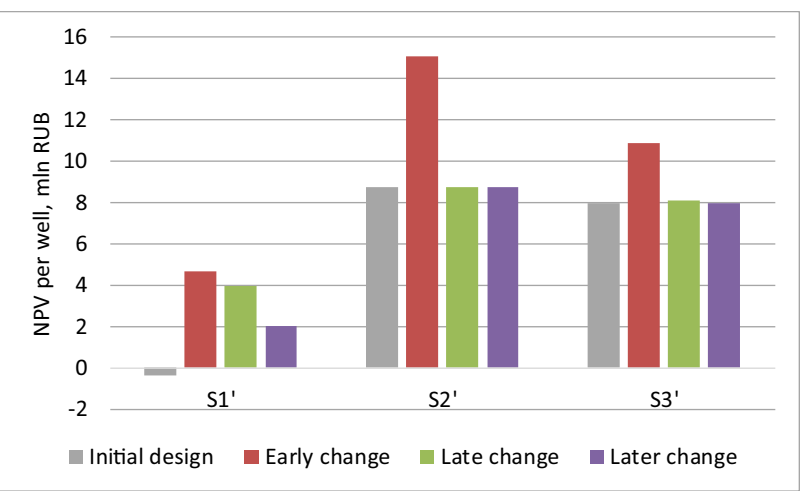

Fig. 12 Performance of the initial and corrected designs for three scenarios $\mathrm{S}^{\prime}, \mathrm{S} 2^{\prime}$ and $\mathrm{S} 3{ }^{\prime}$

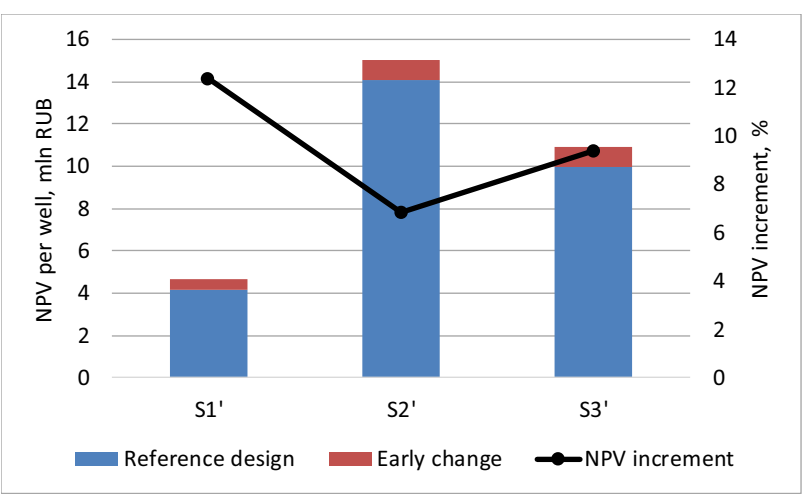

Fig. 13 Comparative performance of early corrected well pad designs and the reference designs for three scenarios $\mathrm{S}^{\prime}, \mathrm{S}^{\prime}{ }^{\prime}$ and $\mathrm{S} 3{ }^{\prime}$ '

for a specific set of parameters; to keep their performance at the highest level, they must be corrected to account for updated conditions. These design corrections upon updates in project parameters represent the framework of the adaptive well pad development. In addition, as the next section demonstrates, it can be shown that in reasonably uncertain conditions, when relevant project parameters are not fixed but represented by probability distributions, configurations with unequal number of wells in clusters consistently outperform configurations with equal number of wells in clusters in terms of economic outcome.

\section{Influence of uncertainty}

To estimate how clustering schemes with equal (the reference design) and unequal (the initial design) number of wells in groups behave and perform in uncertain conditions, the Monte Carlo simulations are used. In the simulations, values of four parameters of every well are not fixed but represented by probability distributions. Three well parameters-the

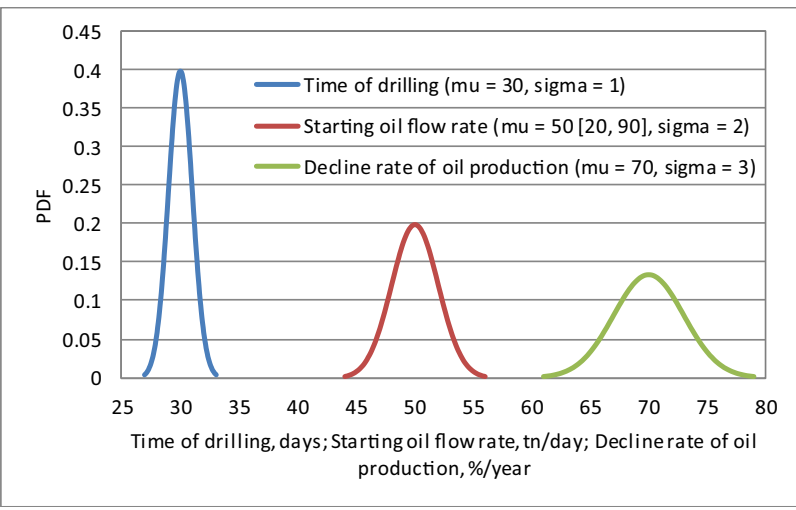

Fig. 14 Probability distribution functions (PDF) for the well drilling time, the starting oil flow rate and the oil production decline rate (the staring oil flow rate is distributed around three values 20,50 and $90 \mathrm{tn} /$ day, and only one distribution around $50 \mathrm{tn} /$ day is shown)

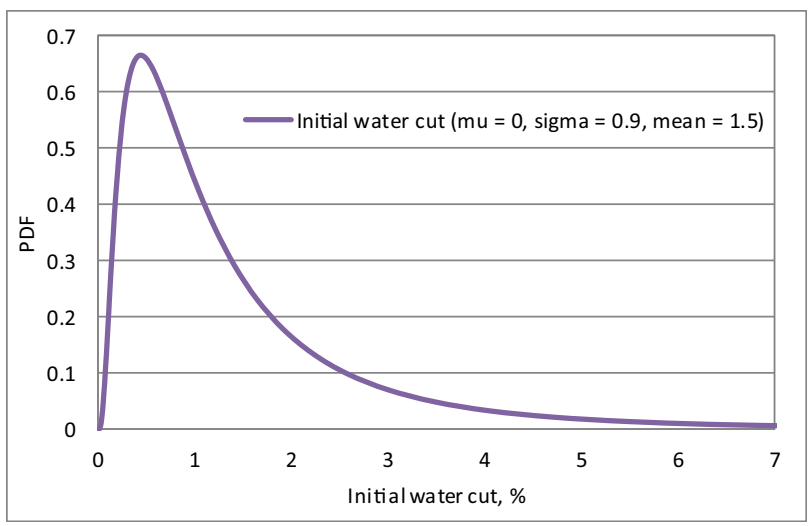

Fig. 15 Probability distribution function (PDF) for the initial water cut

well drilling time, the starting oil flow rate and the oil production decline rate, are distributed normally, as shown in Fig. 14; one parameter-the initial water cut, is distributed log-normally, as shown in Fig. 15. Parameters of the probability distributions are selected more or less arbitrary on basis of author's expertise, which is reasonable for this sort of comparative study. Other well and project parameters are fixed and taken as they are given in Table 1. To construct the cumulative distribution functions for the NPV, 100000 calculations were performed for the reference and for the initial designs for three scenarios S1, S2 and S3.

The cumulative distribution functions for the NPV constructed for the reference designs and the initial designs for three scenarios S1, S2 and S3 are shown in Figs. 16, 17 and 18. In the case of scenario S1, there is only about $40 \%$ chance of getting the NPV $15 \mathrm{mln}$ RUB or more for the reference design, whereas for the initial design, the chance is about $60 \%$. In the case of scenario $\mathrm{S} 2$, there is about $60 \%$ chance of getting the

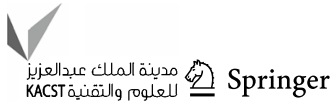


Fig. 16 Cumulative distribution functions (CDF) for the NPV of the drilling projects according to scenario $\mathrm{S} 1$

Fig. 17 Cumulative distribution functions (CDF) for the NPV of the drilling projects according to scenario $\mathrm{S} 2$

Fig. 18 Cumulative distribution functions (CDF) for the NPV of the drilling projects according to scenario $\mathrm{S} 3$
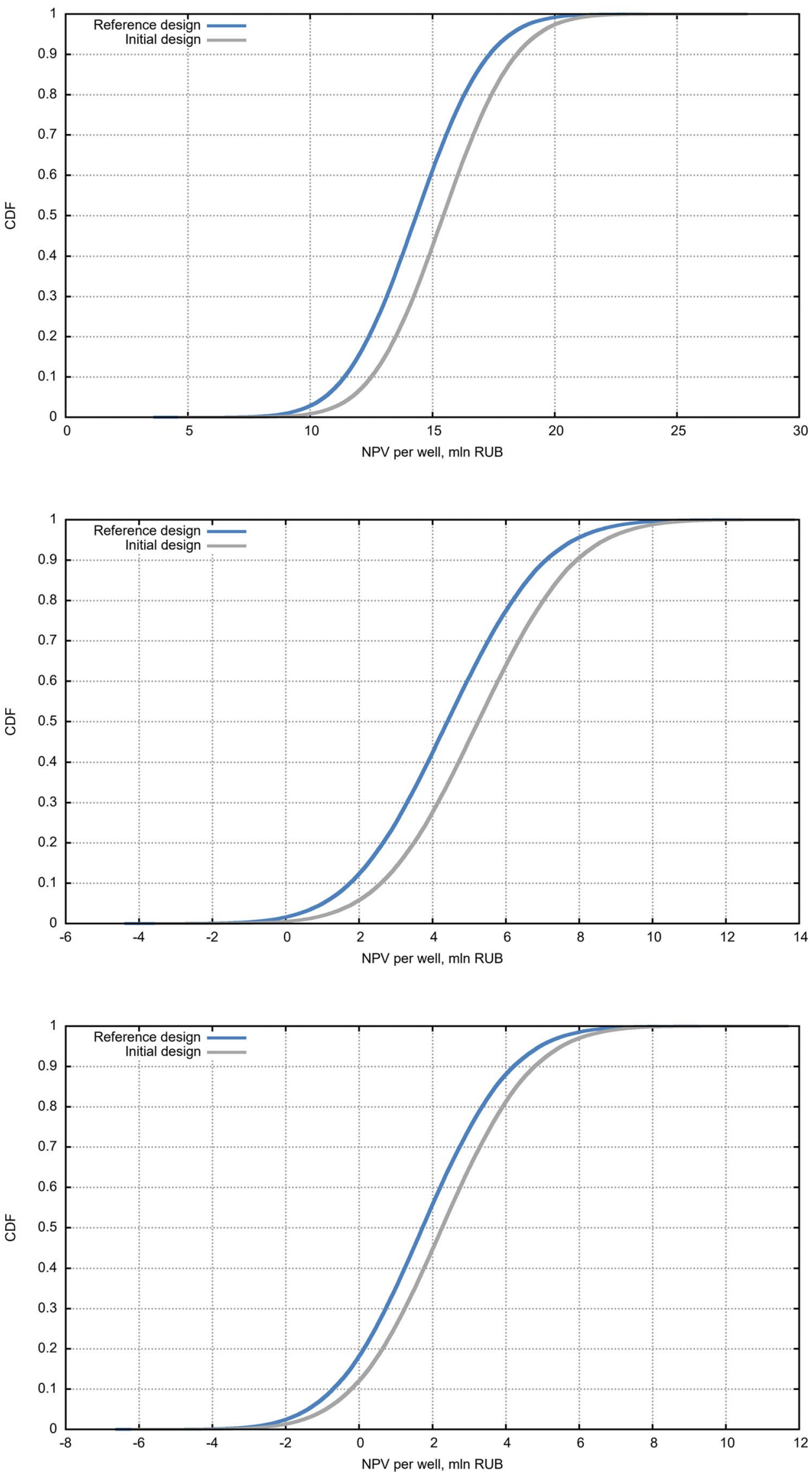
NPV 4 mln RUB or more for the reference design, whereas for the initial design, the chance is about $70 \%$. In the case of scenario $\mathrm{S} 3$, there is about $80 \%$ chance of getting positive NPV for the reference design, whereas for the initial design, this chance is about $90 \%$. Overall, the initial designs have higher probability of getting better economic results than the reference designs, and there is 10 to $20 \%$ percent improvement to probability of ending up with a more profitable drilling project.

\section{Conclusions}

A novel methodology of well pad development was introduced and thoroughly studied. Based on well pad configurations with unequal number of wells, the adaptive well pad development further improves economic performance of well pad drilling projects. The adaptive well pad development enhances the economic results by changing well pad configurations according to updates in parameters with high degree of uncertainty, like the starting oil/gas flow rate and the oil/gas production decline rate.

Combination of the unequal well clustering configurations with the agile methodology (the adaptive well pad development) results in NPV improvements at the level of several to tens of percent. For one of the scenarios used in this study, early corrected well pad design improved the NPV of the initial design by $73 \%$ and was better than the reference design by $7 \%$. Additionally, it was confirmed that configurations with unequal number of wells in clusters outperform configurations with equal number of wells. For drilling scenarios studied in this work, the NPV increments ranged from 8 to $36 \%$ with the initial set of parameters. Moreover, it was found that groupings with unequal number of wells consistently outperform groupings with equal number of wells in uncertain conditions. Results of this research demonstrate that there is 10 to $20 \%$ percent improvement to probability of ending up with a more profitable drilling project when groupings with unequal number of wells are used instead of groupings with equal number of wells.

Funding This research did not receive any specific grant from funding agencies in the public, commercial or not-for-profit sectors.

\section{Compliance with ethical standards}

Conflict of interest There are no competing interests to declare.

Open Access This article is licensed under a Creative Commons Attribution 4.0 International License, which permits use, sharing, adaptation, distribution and reproduction in any medium or format, as long as you give appropriate credit to the original author(s) and the source, provide a link to the Creative Commons licence, and indicate if changes were made. The images or other third party material in this article are included in the article's Creative Commons licence, unless indicated otherwise in a credit line to the material. If material is not included in the article's Creative Commons licence and your intended use is not permitted by statutory regulation or exceeds the permitted use, you will need to obtain permission directly from the copyright holder. To view a copy of this licence, visit http://creativecommons.org/licenses/by/4.0/.

\section{References}

A guide to the project management body of knowledge (PMBOK (R) Guide) Sixth Edition, September 22, 2017, Project Management Institute

Abramov A, Bikbulatov R, Kolesnik I et al (2018) Boosting economic efficiency of pads drilling projects. A comprehensive study of wells groupings and localization of the global maximum. J Petrol Sci Eng 165:212-222. https://doi.org/10.1016/j.petro 1.2018.02.012

Abramov A (2019) Optimization of well pad design and drilling-well clustering. Petroleum Exploration and Development 46(3):614620. https://doi.org/10.1016/S1876-3804(19)60041-8

Agile Practice Guide, October 1, 2017, Project Management Institute

Awad MO, Al Ajmi MF, Al-Mutairi M (2015) Develop new "SIMOPS" procedures to safe workover operations on "PAD". SPE North Africa Technical Conference and Exhibition, Cairo, Egypt, 14-16 September. SPE-175769-MS. https://doi.org/10.2118/175769-MS

Awada A, Santo M, Lougheed D et al (2016) Is That interference? A work flow for identifying and analyzing communication through hydraulic fractures in a multiwell pad. SPE J 21(05):1554-1566. https://doi.org/10.2118/178509-PA

Calderon AJ, Guerra OJ, Papageorgiou LG et al (2015) Preliminary evaluation of shale gas reservoirs: appraisal of different well-pad designs via performance metrics. Ind Eng Chem Res 54(42):10334-10349. https://doi.org/10.1021/acs.iecr.5b01590

Demong KL, Boulton KA, Elgar T et al (2013) The evolution of high density pad design and work flow in shale hydrocarbon developments. SPE eastern regional meeting, Pittsburgh, Pennsylvania, USA, 20-22 August. SPE-165673-MS. https://doi. org/10.2118/165673-MS

Gakhar K, Shan D, Rodionov Y et al (2016) Engineered approach for multi-well pad development in eagle ford shale. Unconventional resources technology conference, San Antonio, Texas, USA, 1-3 August. URTEC-2431182-MS. https://doi.org/10.15530/URTEC $-2016-2431182$

Krome JD, Bloom MH, Swanson AB et al (2015) Revealing the benefits of the intelligent well pad program for onshore shale assets. SPE annual technical conference and exhibition, Houston, Texas, USA, 28-30 September. SPE-174826-MS. https://doi. org/10.2118/174826-MS

Manchanda R, Sharma MM, Holzhauser S (2014) Time-Dependent Fracture-Interference Effects in Pad Wells. SPE Prod Oper 29(04):274-287. https://doi.org/10.2118/164534-PA

Molina O, Zeidouni M (2017) Analytical model to estimate the fraction of fracture hits in a multi-well pad. SPE liquids-rich basins conference-North America, Midland, Texas, USA, 13-14 September. SPE-187501-MS. https://doi.org/10.2118/187501-MS

Ogoke V, Schauerte L, Bouchard G et al (2014) Simultaneous operations in multi-well pad: a cost effective way of drilling multi wells pad and deliver 8 fracs a day. SPE annual technical conference and exhibition, Amsterdam, The Netherlands, 27-29 October. SPE170744-MS. https://doi.org/10.2118/170744-MS

Rafiee M, Soliman MY, Pirayesh E (2012) Hydraulic fracturing design and optimization: a modification to zipper frac. SPE annual technical conference and exhibition, San Antonio, Texas, USA, 8-10 October. SPE-159786-MS. https://doi.org/10.2118/159786-MS

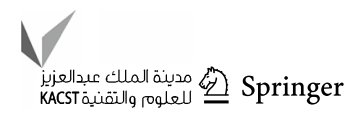


Roussel NP, Sharma MM (2011) Optimizing fracture spacing and sequencing in horizontal-well fracturing. SPE Prod Oper 26(02):173-184. https://doi.org/10.2118/127986-PA

Schofield J, Rodriguez-Herrera A, Garcia-Teijeiro X (2015) Optimization of well pad and completion design for hydraulic fracture stimulation in unconventional reservoirs. EUROPEC 2015, Madrid, Spain, 1-4 June. SPE-174332-MS. https://doi.org/10.2118/17433 2-MS

Stagg TO, Reiley RH (1991) Watchdog: an anti-collision wellhead monitoring system. International arctic technology conference, Anchorage, Alaska, 29-31 May. SPE-22123-MS. https://doi. org/10.2118/22123-MS

Suarez, M., and Pichon, S. 2016. Completion and Well Spacing Optimization for Horizontal Wells in Pad Development in the Vaca Muerta Shale. SPE Argentina Exploration and Production of Unconventional Resources Symposium, Buenos Aires, Argentina, 1-3 June. SPE-180956-MS. https://doi.org/10.2118/180956-MS.
Tolman RC, Simons JW, Petrie DH et al (2009) Method and apparatus for simultaneous stimulation of multi-well pads. SPE hydraulic fracturing technology conference, The Woodlands, Texas, 19-21 January. SPE-119757-MS. https://doi.org/10.2118/119757-MS

White KRJ (2008) Agile project management: a mandate for the changing business environment. Paper presented at PMI Global Congress 2008, Denver, Colorado

Wilson A (2016) Completion and well-spacing optimization for horizontal wells in pad development. J Pet Technol 68(10):54-56. https://doi.org/10.2118/1016-0054-JPT

Publisher's Note Springer Nature remains neutral with regard to jurisdictional claims in published maps and institutional affiliations. 